REVISTA DE DERECHO UNED, núm. 2, 2007

\title{
LA PROTECCIÓN DE LOS DERECHOS HUMANOS DE LOS INMIGRANTES POR EL CONSEJO DE EUROPA: ESPECIAL REFERENCIA A LA JURISPRUDENCIA DEL TEDH*
}

\author{
Claribel de Castro Sánchez**
}

Resumen: En el comienzo del Siglo XXI, Europa se ha convertido en el lugar de destino de miles de inmigrantes ilegales. Esta situación implica un "nuevo" problema social que debe ser resuelto de una forma global por todos los actores implicados. Asimismo, será necesario respetar el standard mínimo internacional de derechos humanos. Estos actores son los Estados Europeos y, también, las organizaciones internacionales europeas, especialmente, la Unión Europea y el Consejo de Europa. Cualquier solución adoptada para resolver el problema debe conciliar los intereses de los países europeos y el respeto de los derechos humanos de los migrantes. En el presente artículo intentamos analizar la labor del Consejo de Europa en este ámbito. Hemos estructurado nuestro trabajo en dos bloques: en primer lugar, analizamos los instrumentos internacionales adoptados por la Organización relativos a los derechos humanos de los migrantes; en segundo lugar, centramos nuestro estudio en las instituciones del Consejo de Europa con competencia en esta materia. Para ello, tendremos en cuenta la labor del Comisario Europeo de Derechos Humanos, la Comisión Europea contra el Racismo y la Intolerancia

* Este trabajo ha sido realizado en el marco del Proyecto de investigación N.: SEJ2004-07939-C03-01 que lleva por título Hacia un sistema judicial internacional: logros y desafíos, financiado por el MEC y dirigido por la Prof. ${ }^{a}$ CONCEPCION EsCOBAR HERNÁNDEZ.

** Doctora en Derecho por la UNED. Profesora Ayudante Doctora de Derecho Internacional Público y Relaciones Internacionales en la Facultad de Derecho de la UNED. 
(ECRI), el Comité para la Prevención de la Tortura (CPT) y el Tribunal Europeo de Derechos Humanos (TEDH).

Palabras claves: Consejo de Europa, derechos humanos, organizaciones internacionales, Tribunal Europeo de Derechos Humanos.

Abstract: In the begining of the XXI Century, Europe has been the destination for thousands of ilegal migrants. This situation implies a «new» social problem wich may be resolve for all the actors involved. Also, it will be necessary respect the international standard minimum of human rights. This actors are European Countries and, also, European International Organizations, especially European Union and Council of Europe. Any solution adopted to resove the problem may conciliate the European countries interest and the respect of migrants human rights. In this paper we try to analyze the labour of Council of Europe in this matter. We have structured our paper in two fields: first, we analyze the international instruments adopted for the Organizatition related to migrants human rights; on the other hand, we focus our study in the institutions of the Council of Europe with competence in this subject. For this purpose, we will take into account the labour of the (European) Commisioner for Human Rights, the European Commission against Racism and Intolerance (ECRI), the Committee for the Prevention of Torture (CPT) and the European Court of Human Rights.

Sumario: I. INTRODUCCIÓN.-II. EL PROCESO CODIFICADOR: 1. Tratados destinados a la protección de los derechos de los migrantes; 2. Tratados no específicos que extienden su protección a los migrantes.-III. LOS ÓRGANOS COMPETENTES: 1. La Asamblea Parlamentaria; 2. El Comité de Ministros; 3. El Comisario de Derechos humanos; 4. La Comisión Europea para el Racismo y la Intolerancia (ECRI); 5. El Comité europeo para la prevención de la tortura y de las penas y tratos inhumanos o degradantes (CPT); 6. El Tribunal Europeo de Derechos Humanos.-IV. A MODO DE RECAPITULACIÓN.

\section{INTRODUCCIÓN}

En este comienzo del Siglo XxI nuevamente Europa es el destino de grandes flujos migratorios. La avalancha de pateras y cayucos procedentes de África y de autobuses de Europa del Este ha provocado ciertos conflictos sociales en los países europeos que deben en- 
frentarse al problema de la inmigración, en gran parte ilegal. Ante esta «nueva realidad social», sobre todo para algunos países que, como España, ha pasado, en muy poco tiempo, de ser un país de emigración a serlo de inmigración, surge la necesidad de adecuación entre las prácticas de estos Estados respecto de los inmigrantes y las exigencias internacionales en materia de protección de los derechos humanos. Así pues, los Estados europeos deben enfrentarse a esta nueva problemática respetando el standard mínimo que impone el Derecho Internacional, tratando de respetar la dignidad de toda persona ${ }^{1}$, independientemente de la legalidad o no de su situación en el territorio de los mismos.

Pero no sólo son los Estados europeos quienes deben enfrentarse a este problema creciente de la inmigración irregular, sino que también se ven afectadas las organizaciones regionales en las que estos países se integran, UE y Consejo de Europa. Todos ellos han llegado a la conclusión de que el problema de la inmigración debe ser abordado desde una perspectiva global, que integre, tanto los intereses de los Estados europeos de destino, como las necesidades de los Estados de origen y los derechos de los migrantes y sus familias ${ }^{2}$. La perspectiva que queremos adoptar en este trabajo es la de la promoción y protección de los derechos humanos por parte del Consejo de Europa en este ámbito. Y es que, como afirma DE TAPIA, "los migrantes irregulares son doblemente víctimas: de situaciones difíciles, sino inviables, en el país de origen, y de carencias graves en las políticas migratorias de los países de tránsito y de destino" ${ }^{3}$, por lo que debe extremarse su protección para evitar, en la medida de lo posible, situaciones traumáticas.

${ }^{1}$ CASTILLO Daudi, M.: Derecho Internacional de los Derechos Humanos, 2. ${ }^{a}$ Edición, Tirant LoBlanch, Valencia, 2006, pp. 34 y 35; RoJo ToRRECILLA, E. (COORD..): Inmigración y mercado de trabajo en la era de la globalización. Estudio de la normativa internacional, comunitaria y española, Lex Nova, Valladolid, 2006, p. 13.

2 Pueden verse, entre otros: Peral, L.: «Límites jurídicos al discurso político sobre control de flujos migratorios: no refoulement, protección en la región de origen y cierre de fronteras europeas", en REEI (www.reei.org), vol 11, 2006; TAPIA, S. DE: "Les nouvelles configurations de la migration irrégulière en Europe», Rapport de conférence 12 et 13 novembre 2002, Conseil de l'Europe, www.coe.int/t/dg3/migration/Documentation. Asimismo, resultan muy interesantes las reflexiones en torno a la "naturaleza" de las migraciones por la Prof. ${ }^{\text {. }}$ GARCía PICAZO, "Migraciones: entre la intolerancia y la utopía. Sobre la globalización de la "cultura de la pobreza»", en REEI, (www.reei.org), vol. 11, 2006.

3 TAPIA, S. DE: «Les nouvelles configurations de la migration irrégulière en Europe», Rapport de conférence 12 et 13 novembre 2002, op. cit.. 
El Consejo de Europa, tal y como reza el preámbulo de su Estatuto firmado en Londres en 1949, está dirigido a consolidar la paz, basada en la justicia y la cooperación internacional, en la adhesión a los valores espirituales y morales que son la fuente de la libertad individual, la libertad política y el imperio del Derecho y en la realización progresiva de estos ideales y en interés del progreso social y económico. Para ello, se establecen como fines de la organización realizar «una unión más estrecha entre sus miembros a fin de salvaguardar y de promover los ideales y los principios que son su patrimonio común y favorecer su progreso económico y social» (art. 1.a) y «perseguir [...] la protección y desarrollo de los derechos humanos y las libertades fundamentales» (art. 1.b).

De todo lo dicho se deriva la importancia que la promoción y protección de los derechos humanos tiene en el marco del Consejo de Europa, aspecto en el que, en palabras del Prof. DíEz DE VELASCo, la organización, «a través del Convenio Europeo de Derechos Humanos ha llegado a una mayor perfección $»^{4}$. Y es que, tal y como se recoge en el art. 3 del Estatuto del Consejo de Europa, los Estados parte deben reconocer «el principio en virtud del cual toda persona situada bajo su jurisdicción debe disfrutar los derechos humanos y las libertades fundamentales». Esta idea de partida es la que fundamenta el sentido de este artículo: conjugar la protección de los derechos humanos y la realidad de la inmigración. Así pues, nos centraremos en dos de los aspectos de la acción del Consejo de Europa: en la labor de codificación en materia de derechos humanos de los migrantes y en la labor de los órganos del Consejo de Europa con competencia en la materia, con especial referencia al Tribunal Europeo de Derechos Humanos.

\section{EL PROCESO CODIFICADOR}

El inicio del proceso codificador en materia de derechos humanos en el ámbito del Consejo de Europa se inicia en el mismo momento en que nace la idea de dicha organización: la Comisión jurídica del Movimiento Europeo preparó un primer proyecto de Convención que siguió su curso, ya en el seno del Consejo, durante los años 1949 y 1950, siendo adoptada finalmente en noviembre de 1950 en Roma. Así, el CONVENIO EUROPEO PARA LA PROTECCION DE LOS DERECHOS HUMA-

${ }^{4}$ Vid. DíEz DE Velasco Vallejo, M.: Las Organizaciones Internacionales, 14. ${ }^{\text {a }}$ Ed., Madrid, Tecnos, 2006, pp. 467 y 469. 
NOS Y LAS LIBERTADES FUNDAMENTALES (en adelante CEDH) se convierte en el primer texto internacional jurídicamente vinculante en materia de Derechos Humanos ${ }^{5}$. A partir de ese momento y hasta hoy son muchos los textos relativos a derechos humanos adoptados en el marco de esta organización. Algunos de ellos se dedican a la protección genérica de todos los derechos (sean estos civiles y políticos o económicos, sociales y culturales ${ }^{6}$ o los llamados derechos de tercera generación o derechos de solidaridad) mientras que otros se destinan bien a la protección de los individuos frente a las formas más graves de violación de determinados derechos, bien a la protección de los derechos de determinados grupos vulnerables ${ }^{7}$. Dentro de estos grupos vulnerables se encuentran las poblaciones migrantes, en las que nosotros nos hemos centrado como objeto de este artículo.

5 Como es sabido, la DECLARACIÓN UNIVERSAL DE DERECHOS HUMANOS fue adoptada por la Asamblea General de las Naciones Unidas dos años antes (Resolución 217 A (III), de 10 de diciembre de 1948). La forma de aprobación de la misma implicaba, al menos formalmente, la falta de oponibilidad jurídica. A pesar de ello, tal y como ha afirmado la Prof. ${ }^{a}$. EsCOBAR HERNÁNDEZ, «lo cierto es que la Declaración Universal ha experimentado una evolución tendente a permitir cierta oponibilidad de la misma a los Estados, especialmente por vía consuetudinaria y en el plano de los principios que subyacen en la misma, esencialmente el del respeto y protección de los atributos esenciales del ser humano en el marco del estado de derecho" (Vid. "La Protección Internacional de los Derechos Humanos (I)", en Instituciones de Derecho Internacional Público, (Díez de Velasco Vallejo, M.), 15. ${ }^{a}$ Ed., Madrid, Tecnos, 2006, p. 637). La adopción, en el año 1966, del PACTO INTERNACIONAL DE DERECHOS CIVILES Y POLfTICOS y del PACTO INTERNACIONAL DE DERECHOS ECONOMICOS, SOCIALES Y CULTURALES - que no entrarán en vigor hasta 1976 - vendrán a paliar esa falta de oponibilidad.

6 En este marco, fundamentalmente la CARTA SOCIAL EUROPEA - 18/10/1961- (modificada por el PROTOCOLO ADICIONAL -5/05/1988-, que añada nuevos derechos a garantizar por parte de la Carta, el PROTOCOLO DE REFORMA-21/10/1991-, que supone la mejora del mecanismo de control previsto por la Carta, y el PROTOCOLO ADICIONAL POR EL QUE SE ESTABLECE EL SISTEMA DE QUEJAS COLECTIVAS -09/11/1995-) y la CARTA SOCIAL EUROPEA REVISADA -3/5/1996-.

7 Entre los del primer grupo ocupa un lugar destacado la CONVENCION EUROPEA PARA LA PREVENCIÓN DE LA TORTURA Y LOS TRATOS O PENAS INHUMANOS O DEGRADANTES 26/11/1989 (Modificado por el PROTOCOLO N. ${ }^{\circ} 1$ - 4/11/1993-, que permite la adhesión a la Convención de Estados no miembros del Consejo de Europa, y el PROTOCOLO N. ${ }^{\circ} 2$ -4/11/1993, que introduce modificaciones técnicas respecto del Comité Europeo para la prevención de la tortura y los tratos o penas inhumanos y degradantes). Por lo que se refiere al segundo grupo, cabe destacar, entre otras, la CONVENCION EUROPEA SOBRE EL ESTATUTO LEGAL DE LOS TRABAJADORES MIGRANTES -24/11/1977-; la CONVENCION SOBRE LA PARTICIPACIOON DE LOS EXTRANJEROS EN LA VIDA PÚBLICA A NIVEL LOCAL - 5/2/1992; CONVENCIÓN MARCO PARA LA PROTECCIÓN DE LAS MINORIAS NACIONALES -1/2/1995-; CONVENCIÓN EUROPEA SOBRE EL EJERCICIO DE LOS DERECHOS DEL NIÑO -25/1/1996-; CONVENCIÓN DEL CONSEJO DE EUROPA DE LUCHA CONTRA LA TRATA DE SERES HUMANOS $-16 / 05 / 2005-$ 
En la línea de lo dicho vamos a dividir nuestra exposición respecto de los textos existentes en el marco de esta organización en dos grupos: tratados que se destinan directamente a la protección de los derechos de los inmigrantes y tratados que, si bien no tienen como destinatarios específicos a los inmigrantes si les confieren cierta protección.

\section{TRATADOS DESTINADOS A LA PROTECCIÓN DE LOS DERECHOS DE LOS MIGRANTES.}

A. Acuerdo Europeo Relativo a la supresión de visas para los refugiados (04/09/1959), adoptado en Estrasburgo el 20 de abril de 1959, entró en vigor el 4 de septiembre de 1960 (3 ratificaciones) y en la actualidad ha sido ratificado por 22 Estados entre los que sí se encuentra España ${ }^{8}$.

El objeto de este acuerdo es facilitar los viajes de los refugiados residentes en el territorio de las Partes. Para ello se prevé que los refugiados puedan entrar sin necesidad de visado en el territorio de otro Estado Parte para las estancias de tres o más meses, siempre que éstas no impliquen actividades lucrativas ${ }^{9}$.

B. Convención Europea sobre la repatriación de menores (28/05/1970), adoptada en La Haya el 28 de mayo de 1970, aún no ha entrado en vigor ya que únicamente la han ratificado dos Estados (Turquía e Italia), requiriendo el artículo 23 de la Convención, 3 ratificaciones para su entrada en vigor.

El objeto de la misma es permitir a los Estados contratantes solicitar a otro Estado contratante la repatriación de un menor por alguna de las razones establecidas en el texto: a) la presencia del menor

8 Ratificado el 30 de junio de 1982.

9 En el mismo se prevé que los refugiados serán readmitidos en todo momento por el Estado Parte cuyas autoridades hayan dispensado un título de viaje cuando lo demande otro Estado Parte. Los Estados Europeos que además sean miembros de la UE, habrán de conciliar las obligaciones derivadas de este tratado con las que se deriven del propio Derecho Comunitario Europeo, en el marco del espacio de libertad, la seguridad y la justicia, como la Directiva 2005/85 sobre normas mínimas para los procedimientos que deben aplicar los Estados miembros para conceder o retirar la condición de refugiado. Para un comentario de la misma puede consultarse QuESADA ALCALÁ, C.: «Las normas mínimas para los procedimientos que deben aplicar los Estados miembros para conceder o retirar la condición de refugiado. Comentario a la Directiva 2005/85/CE del Consejo, de 1 de diciembre de 2005", en RGDE (www.iustel.com), n. ${ }^{\circ} 12$, enero 2007. 
sobre el territorio del Estado requerido es contraria a la voluntad de la persona o personas que detentan sobre él la autoridad paterna; b) la presencia del menor sobre el Estado requerido es incompatible con una medida de protección o reeducación adoptada a su respecto por las autoridades del Estado requirente; c) la presencia del menor sobre el territorio del Estado requirente es necesaria en razón de un procedimiento destinado a adoptar medidas de reeducación respecto del mismo.

La Convención se aplica igualmente a la repatriación de los menores que se encuentran sobre el territorio de un Estado contratante debido a que éste considera su presencia contraria a sus propios intereses o a los intereses de los menores y por tanto que su legislación le permite expulsarlo de su territorio.

C. La Convención Europea relativa al estatuto jurídico de los trabajadores migrantes (24/11/1977) ${ }^{\mathbf{1 0}}$, adoptada en Estrasburgo el 24 de noviembre de 1977, entró en vigor el 1 de mayo de 1983 (5 ratificaciones) y en la actualidad ha sido ratificado por nueve Estados, entre los que se cuenta España ${ }^{11}$.

El texto se dedica a los principales aspectos de la situación jurídica de los trabajadores migrantes, en particular, la contratación, los exámenes médicos y profesionales, los viajes, los permisos de residencia, los permisos de trabajo, la reagrupación familiar, las condiciones de trabajo, la seguridad social, la asistencia social y médica, la expiración de los contratos de trabajo, el despido y el reempleo.

Sobre la base de este convenio se ha creado un Comité Consultivo de Expertos -compuesto por un representante de cada Estado parte en el convenio- para examinar los informes sometidos por las Partes (respecto de la aplicación de la Convención). Sobre la base de estos

10 Un estudio en profundidad de la importancia y significación de esta Convención puede consultarse en GUILD, E.: La Convention Européenne relative au statut juridique du travailleur migrant (1977). Une analyse de son champ d'application et de sa portée actuelle, mars 1999, (www.coe.int/t/migration/Documentation).

11 España ratificó el 6 de mayo de 1980. Uno de los aspectos más sorprendentes en torno a este tratado es el bajo índice de ratificación. Al respecto, la Prof. a. GuILD ( $L a$ Convention Européenne relative au statut juridique du travailleur migrant (1977). Une analyse de son champ d'application et de sa portée actuelle, op. cit., p. 17) considera que tal ausencia se debe a que "con la firma del Tratado de Amsterdam, la regulación de la permanencia de personas procedentes de países terceros sobre el territorio de los Estados miembros de la Unión Europea ha devenido en competencia comunitaria. Las disposiciones relativas a la estancia de extranjeros serán, en consecuencia, elaboradas en el seno de las instituciones comunitarias y adoptadas conforme a estas normas europeas». 
informes el Comité Consultivo presenta informes al Comité de Ministros.

\section{TRATADOS NO ESPECÍFICOS QUE EXTIENDEN SU PROTECCIÓN A LOS MIGRANTES}

\section{A. Convenio Europeo de Derechos Humanos y Libertades} Fundamentales (CEDH) ${ }^{\mathbf{1 2}}$, adoptado en Roma el 4 de noviembre de 1950, entró en vigor el 3 de septiembre de 1953 (10 ratificaciones) siendo Parte del mismo en la actualidad los 46 Estados miembros del Consejo de Europa ${ }^{13}$.

Como ya hemos indicado, es el texto más importante en el marco de la protección de los derechos humanos tanto universales como regionales, ya que en su seno se ha creado un órgano judicial internacional, el TRIBUNAL EUROPEO DE DERECHOS HUMANOS (TEDH), al que pueden acudir directamente los particulares ${ }^{14}$.

A pesar de que el CEDH no contiene ninguna disposición específica respecto de la inmigración, algunas de sus disposiciones si que han sido utilizadas para litigios vinculados con el acceso y salida del territorio de un Estado Parte ${ }^{15}$ o a cualquier otra situación en la que

12 Ha sido modificado por catorce Protocolos Adicionales. Ocho de ellos (Protocolos $2,3,5,8,9,10,11$ y 14) se han ocupado de modificar el sistema de protección de los derechos mientras que los otros seis (Protocolos 1, 4, 6, 7, 12 y 13) han supuesto una ampliación de derechos. A los efectos de este trabajo, de este segundo tipo de protocolos, los que suscitan mayor interés son los Protocolos 4 y 7. El PROTOCOLO N. ${ }^{\circ} 4$ -16/09/1963-, entró en vigor el 2 de mayo de 1968 y prohíbe la expulsión colectiva de extranjeros. El PROTOCOLO N. ${ }^{\circ} 7-22 / 11 / 1984$, entró en vigor el 1 de noviembre de 1988 y recoge el derecho de los extranjeros a no ser expulsados del país en que residen regularmente salvo con las debidas garantías previstas en el propio Protocolo. España, si bien ha firmado ambos protocolos, el 23 de febrero de 1978 el primero y el 22 de noviembre de 1984 el segundo, aún no ha ratificado ninguno de ellos.

13 España ratificó el 4 de octubre de 1979.

14 A partir de la entrada en vigor del Protocolo 11 al CEDH, el 1 de noviembre de 1998, se producen dos novedades que van a ser de una gran importancia. Por un lado, se termina con la dualidad de órganos (Comisión Europea de Derechos Humanos y Tribunal Europeo de Derechos Humanos) configurándose un nuevo TEDH. Por otro lado, se establece la posibilidad de cualquier individuo que se encuentre bajo la jurisdicción de un Estado Parte y crea ser víctima de la violación de un derecho de los recogidos en el CEDH de presentar una demanda ante el TEDH.

15 Vid. CARLIER, J-Y. ET SAROLÉ, S.: "Évolutions Jurisprudentielles", en Inmigration and Asylum Law of the EU: current debates (DIR. CARLIER, J-Y ET DE BRUYCHER, P.), Bruxelles, Bruylant, 2005, p. 11. Por otra parte si que es cierto que alguna de las normas del ámbito del CEDH se destinan a la protección específica de extranjeros, como es el caso del artículo 4 del Protocolo 4 que prohíbe las expulsiones colectivas de ex- 
un extranjero se encuentre implicado. Ello es posible porque a la luz del artículo 1 del CEDH «las Altas Partes Contratantes reconocen a toda persona dependiente de su jurisdicción los derechos y libertades definidos en el Título I del presente Convenio». Por tanto, a la luz de estas palabras, la nacionalidad de la víctima resulta irrelevante para la admisibilidad de la demanda; por otra parte, tal y como ha reconocido el TEDH en el Asunto D. c. Reino Unido (sentencia de 2 de mayo de 1997), la ilegalidad de la estancia del extranjero no excluye la aplicabilidad de la Convención que debe aplicarse al extranjero dado que se encuentra físicamente en el territorio de un Estado Parte $^{16}$. En definitiva, el CEDH se aplica a cualquier persona, nacional o extranjero, «legal» o «ilegal», que se encuentre bajo la jurisdicción de un Estado parte.

En esta línea, es interesante analizar la labor realizada por el TEDH en el marco de nuestro trabajo, cuestión que abordaremos al hablar de los órganos encargados de la protección de derechos humanos.

B. Convención Europea para la prevención de la tortura y de las penas y tratos inhumanos o degradantes (26/11/1987), adoptada en Estrasburgo el 11 de noviembre de 1987, entró en vigor el 1 de febrero de 1989 (7 ratificaciones) y en la actualidad ha sido ratificada por todos los Estados miembros del Consejo de Europa ${ }^{17}$ además de por un Estado no miembro, Montenegro.

La Convención prevé la creación del COMITÉ EUROPEO PARA LA PREVENCION DE LA TORTURA Y DE LAS PENAS Y TRATOS INHUMANOS O DEGRADANTES (en adelante CPT), compuesto por personalidades independientes (tantas como Estados Parte) al que se habilita para visitar todos los lugares donde se encuentran personas privadas de libertad por una autoridad pública. Este Comité puede formular recomendaciones y sugerencias o mejoras a los Estados parte para reforzar la protección de las personas frente a la tortura y los tratos inhumanos y degradantes.

Dado que la competencia "espacial" del Comité se establece, por el art. 2 del Convenio, respecto de «todo lugar sujeto a la jurisdicción

tranjeros, y el artículo 1 del Protocolo 7 que garantiza los derechos procesales a las personas objeto de una medida de expulsión.

16 Vid. Carlier, J-Y. ET SaroléA, S.: «Évolutions Jurisprudentielles», en Inmigration and Asylum Law of the EU: current debates, op. cit., p. 12; LEACH, P.: Taking a Case to the European Court of Human Rights, $2^{\text {nd }}$ Edition, Oxford University Press, 2005, p. 179.

17 España ratificó el 2 de mayo de 1989. 
del Estado en el que las personas estén privadas de libertad por una autoridad pública», estos lugares incluyen prisiones y correccionales, comisarías de policía, lugares de detención para extranjeros, hospitales psiquiátricos y residencias de ancianos o de personas discapacitadas. Por lo tanto, en los informes del Comité se hace referencia a la situaciones relativas a los inmigrantes que pueden ser contrarias a la Convención.

C. Convención del Consejo de Europa sobre la lucha contra la trata de seres humanos (16/05/2005), adoptada en Varsovia el 16 de mayo de 2005, aún no ha entrado en vigor ya que únicamente ha sido ratificada por un Estado, Moldavia, de los diez que exige su artículo 42.3 para la entrada en vigor, ocho de los cuales deben ser Estados Parte del Consejo de Europa ${ }^{18}$.

La Convención es un tratado global fijado, esencialmente, sobre la protección de las víctimas de la trata y la garantía de sus derechos. Pretende, asimismo, la prevención de la trata, así como la persecución de los traficantes.

La Convención se aplica a todas las formas de trata, sea ésta nacional o transnacional, esté o no ligada al crimen organizado. Asimismo se aplica independientemente de quienes sean las víctimas: mujeres, hombres o niños, e independientemente de cual sea la forma de explotación: explotación sexual, trabajos o servicios forzados, etc.

Para conseguir sus objetivos prevé la puesta en marcha de un mecanismo de seguimiento independiente que garantice el respeto de sus disposiciones por los Estados Parte: el GRUPO DE EXPERTOS SOBRE LA LUCHA CONTRA LA TRATA DE SERES HUMANOS (GRETA), previsto en el artículo 36.

\section{LOS ÓRGANOS COMPETENTES}

Son varios los órganos del Consejo de Europa que ostentan competencias en el ámbito de la protección de los derechos humanos, de forma genérica, así como en el ámbito más específico de los derechos de los migrantes. Estos órganos pueden ser, bien creados por el propio Estatuto de la Organización, o bien por un convenio en materia de derechos humanos. Aquí haremos referencia básicamente a los si-

${ }^{18}$ Este tratado está abierto a la firma de los Estados miembros, los Estados no miembros que han participado en su elaboración y a la Comunidad Europea y a la adhesión de otros Estados no miembros. 
guientes: a la Asamblea Parlamentaria y especialmente a su Comisión de las migraciones, los refugiados y la población (AS/MIG), al Comité de Ministros, al Comisario de Derechos Humanos, a la Comisión Europea para el Racismo y la Intolerancia (ECRI), al Comité europeo para la prevención de la tortura y de las penas y tratos inhumanos o degradantes (CPT) y al Tribunal Europeo de Derechos Humanos (TEDH).

\section{LA ASAMBLEA PARLAMENTARIA}

Denominada así desde 1974 (antes Asamblea consultiva), es el órgano deliberante del Consejo de Europa y está facultada para discutir las cuestiones de su competencia y adoptar recomendaciones ${ }^{19}$. Para el cumplimiento de sus competencias puede nombrar Comités o comisiones a quienes se les encomienda el examen de cuestiones concretas que se estimen oportunas. Basándose en los informes elaborados por tales órganos, la Asamblea adopta sus recomendaciones. En esta línea, y para lo que a nosotros nos interesa, la Asamblea ha creado la AS/MIG.

A. La Comisión de las migraciones, los refugiados y la población (AS/MIG). Desde las sesiones ordinarias de la Asamblea de 1950 y 1951 se constituyeron dos comisiones especiales para estudiar la problemática de los refugiados. En diciembre de 1951 la Asamblea decidió que los problemas a los que debían hacer frente estas comisiones eran suficientemente importantes y "durables" para justificar la creación de una nueva comisión general. Esta comisión fue creada primeramente bajo el nombre de COMISION DE LA POBLACION Y DE LOS REFUGIADOS en la apertura de la sesión ordinaria de 1952. En 1979, a través de la Resolución 685 de la Asamblea Parlamentaria, se redenominó COMISIÓN DE LAS MIGRACIONES, DE LOS REFUGIADOS Y DE LA DEMOGRAFIA para reflejar su interés creciente por los problemas generales de la migración. En 2003 la palabra «demografía» fue sustituida por "población" con la intención de recalcar sus principales ámbitos de actuación, recibiendo pues, desde ese momento el nombre de CoMISIOON DE LAS MIGRACIONES, LOS REFUGIADOS Y LA POBLACION. Esta compuesta por 83 miembros (parlamentarios de la Asamblea Parlamentaria del Consejo de Europa).

19 Estas recomendaciones pueden estar dirigidas o bien al Comité de Ministro, o a la opinión pública en general o a otras organizaciones internacionales. Puede deliberar cualquier cuestión bien de oficio o a instancia del Comité de Ministros. 
A través de la Resolución 1425 (2005), la Asamblea Parlamentaria procedió a revisar los mandatos de todas sus comisiones. Por lo que se refiere a la que nos ocupa, esta revisión implica que el mandato actual de la misma es el que sigue:

1. Trata todas las cuestiones relativas a las políticas en materia de migraciones, refugiados y población. Se funda en una cooperación europea más estrecha en estos ámbitos - así como, llegado el caso, en una cooperación con países no europeos- y propone medidas en este sentido.

2. Examina, en particular:

a. Las cuestiones relativas a las migraciones y a los refugiados en Europa y en otras partes del mundo, lo que incluye el problema de los demandantes de asilo y de los desplazados internos, así como la estrecha cooperación necesaria entre país de origen, de tránsito y de destino.

b. Las tendencias demográficas en Europa y en otras partes del mundo, así como sus repercusiones sociales y económicas.

c. Las relaciones comunitarias en las sociedades multiculturales, lo que comprende la situación de la integración de los trabajadores inmigrantes y de sus derechos sociales, económicos y políticos.

d. Las cuestiones humanitarias y el derecho humanitario.

3. Sigue las actividades de las organizaciones europeas e internacionales pertinentes tales como ACNUR, la Comisión mundial sobre las migraciones internacionales de Naciones Unidas, el Fondo de las Naciones Unidas para la Población (FNUP), el CICR, la OIM, la OIT y la Oficina de seguridad y de trabajo de las Naciones Unidas para los refugiados de Palestina en el Oriente Próximo (UNRWA), con las que mantiene relaciones de trabajo.

4. Representa a la Asamblea ante los Comités de expertos intergubernamentales pertenecientes al Consejo de Europa y sigue sus trabajos.

Los informes realizados por la Comisión sirven como base para las recomendaciones y resoluciones que adopta la Asamblea Parlamentaria ${ }^{20}$. Entre los informes que se encuentran en curso de elabo-

${ }^{20}$ Así el Informe sobre derechos fundamentales de los migrantes irregulares (Doc. 10924, de 4 de mayo de 2006) ha servido de base para la Recomendación 1755 (2006), 
ración en el seno de la COMISIÓN DE LAS MIGRACIONES, LOS REFUGIADOS Y LA POBLACIÓN cabe resaltar los que versan sobre las siguientes cuestiones: a) los derechos fundamentales de los inmigrantes irregulares o clandestinos; b) la imagen de los inmigrantes, refugiados y demandantes de asilo dada por los medios; c) la creación de centros de tránsito fuera de la Unión Europea; d) la inmigración proveniente del África subsahariana.

\section{EL COMITÉ DE MINISTROS}

Es el órgano más importante de la organización y, en esta línea tiene competencia general. Por tanto, tiene competencia en materia de derechos humanos. En esta materia, puede adoptar recomendaciones dirigidas a los Estados y concluir acuerdos.

Así, en mayo de 2005, siguiendo el informe presentado por el Comité ad hoc sobre los aspectos jurídicos del asilo territorial, de los refugiados y los apartidas (CAHAR), el Comité de Ministros adoptó los VEINTE PRINCIPIOS DIRECTRICES DEL RETORNO FORZADO.

Por otra parte, el Comité de Ministros adoptó el texto de la CONVENCIÓN DEL CONSEJO DE EUROPA SOBRE LA LUCHA CONTRA LA TRATA DE SERES HUMANOS, atendiendo las presiones recibidas desde distintos sectores de la sociedad civil, esencialmente desde organizaciones como Anti-Slavery International y Amnistía Internacional. Y es que el número de personas de la región del Consejo de Europa afectadas por esta forma contemporánea de esclavitud ha aumentado espectacularmente en los últimos diez años por lo que en el momento actual

de 27 de junio, sobre los derechos humanos de los migrantes irregulares (http://assembly.coe.int/mainf.asp?Link=/documents/). En la misma, la Asamblea Parlamentaria recogía una serie de recomendaciones al Comité de Ministros: «3.1. que instruya a los comités intergubernamentales correspondientes para establecer una lista de derechos mínimos para los migrantes irregulares, que incluya derechos civiles y políticos y económicos, sociales y culturales a fin de preparar una recomendación que sea adoptada por el propio Comité de Ministros; 3.2. que instruya al Comité Europeo de las Migraciones para celebrar una mesa redonda sobre el estado de ratificaciones por parte de los Estados miembros del Consejo de Europa de la Convención de las Naciones Unidas sobre los derechos de todos los trabajadores migrantes y los miembros de sus familias, con el fin de analizar los obstáculos a los que se enfrentan los Estados para ratificar este tratado; 3.3. que revise la eficacia de los instrumentos sobre derechos humanos relevantes para la protección de los derechos de los migrantes irregulares, en particular la Carta Social Europea y la Carta Social Europea Revisada, con el fin de examinar si es necesario fortalecer los instrumentos de derechos humanos para proteger los derechos de los migrantes irregulares de manera más efectiva». 
constituye un problema de gran magnitud. De hecho, tal como afirma la directora de Anti-Slavery International, «la trata de seres humanos es en sí misma una violación grave de derechos humanos. Constituye una ofensa a la dignidad e integridad del ser humano y, por su misma naturaleza, que entraña coacción, engaño o ambas cosas, así como explotación, somete a las víctimas a una variedad de abusos contra los derechos humanos. Sin embargo, con demasiada frecuencia las autoridades confunden a las personas objeto de trata con migrantes indocumentados e ilegales, las tratan como si fueran delincuentes, en vez de víctimas de graves abusos contra los derechos humanos, y las envían rápidamente de regreso a su país de origen, donde en muchos casos están expuestas a sufrir represalias o a ser de nuevo objeto de trata. Esta actuación frustra, además, los esfuerzos por llevar a los responsables de la trata ante la justicia».

Además, el Comité de Ministros ha creado el COMITÉ EUROPEO SOBRE LAS MIGRACIONES (CDMG) ${ }^{21}$. La larga lista de competencias que se le atribuyen a este Comité, hace que sea necesaria la participación de expertos de muy diversa naturaleza. Así, serán miembros del Comité los representantes designados por los Estados Miembros, que pueden provenir de los Ministerios de Asuntos Exteriores, Ministerio del Interior, Ministerio de Asuntos Sociales y Trabajo, Ministerio de Inmigración, etc. Asimismo, pueden participar como invitados algunos órganos del Consejo de Europa (la Asamblea Parlamentaria o el Banco de Desarrollo del Consejo de Europa), de la Unión Europea (Consejo de la UE o la Comisión Europea), así como otras organizaciones internacionales (OIT, OSCE, OECD, etc.) y Estados no Miembros (Canadá, México, Santa Sede). Su objetivo fundamental es desarrollar la cooperación europea sobre migración, la situación y la integración social de las poblaciones migrantes y los refugiados y las relaciones comunitarias. Es importante pues prepara las recomendaciones del Comité de Ministros en la materia de que es competente, además de constituir un importante foro de discusión.

\section{EL COMISARIO DE DERECHOS HUMANOS}

Creada la figura por la Reunión de Jefes de Estado y de Gobierno de octubre de 1997, celebrada en Estrasburgo, la primera elección se

21 Las reglas internas de funcionamiento del comité, se encuentran reguladas en la Resolución del Comité de Ministros Res(2005)47F, de 14 de diciembre de 2005, sobre los comités y los órganos subordinados, su mandato y su método de trabajo (www. coe.int/t/cm/adoptedTexts_fr.asp\#P89_7136) 
celebró en 1999, siendo elegido el español Álvaro Gil-Robles, que ha sido sustituido, el 1 de abril de 2006, por el sueco Thomas Hammarberg $^{22}$.

Sus funciones, tal y como se desprende de la Resolución (99) 50, de 7 de mayo, son las siguientes: a) promover en los Estados Miembros la educación y la sensibilización en materia de derechos humanos; b) identificar las eventuales insuficiencias tanto del Derecho como de la práctica de los Estados miembros relativas a los derechos humanos; c) contribuir a la promoción y al respeto efectivo así como al pleno goce de los derechos humanos enunciados en los instrumentos del Consejo de Europa.

Para cumplir con sus funciones, el Comisario de Derechos Humanos cuenta con los siguientes instrumentos o mecanismos: a) realizar visitas a cada Estado Miembro para formarse una idea de conjunto respecto de la situación de los derechos humanos en el mismo, finalizada la cual elaborará un informe que puede contener recomendaciones para los Estados; b) organizar seminarios y conferencias para promover la educación y la sensibilización en materia de derechos humanos, al final de éstos también puede adoptar recomendaciones dirigidas a los Estados; c) elaborar dictámenes respecto de proyectos de ley en materia de derechos humanos de los Estados miembros, tanto de oficio como a instancia de los propios Estados.

Así, en el ámbito que hoy nos interesa son varias las acciones del Comisario de Derechos Humanos que merecen ser resaltadas.

En 2001, entre los días 20 y 22 de junio, se celebró en Estrasburgo un seminario bajo los auspicios del Comisario sobre los principios de derechos humanos aplicables a la retención de los inmigrantes que desean entrar en el territorio de un Estado Miembro del Consejo de Europa y la ejecución de las decisiones de expulsión, en el que participaron ONGs, expertos gubernamentales así como el ACNUR. Basándose en las conclusiones del Seminario, el Sr. Gil-Robles adoptó la Recomendación relativa a los derechos de los extranjeros que desean entrar en el territorio de los Estados miembros del Consejo de Europa y a la

22 Es elegido por la Asamblea Parlamentaria por mayoría de votos entre los componentes de una terna presentada por el Comité de Ministros, teniendo que ser los candidatos nacionales de uno de los Estados del Consejo de Europa y expertos de reconocido prestigio en materia de derechos humanos. Su mandato es de seis años y no es renovable. El 5 de octubre de 2005 la Asamblea Parlamentaria procedió a la elección del nuevo Comisario de Derechos Humanos. 
ejecución de las decisiones de expulsión (CommDH/Rec(2001)1, de 19 de septiembre) ${ }^{23}$, de la que cabe destacar las siguientes directrices dirigidas a los Estados para que las tengan en cuenta tanto en sus legislaciones como en sus prácticas:

Por lo que se refiere a los Derechos de los extranjeros al presentarse en la frontera de un Estado miembro, la recomendación establece que: a) Todo aquel que se presente en la frontera de un Estado miembro tendrá derecho a ser tratado con respeto a su dignidad humana, en lugar de ser considerado automáticamente delincuente o culpable de fraude; b) Desde su llegada, todo aquel cuya entrada se cuestione, deberá hacerse entender, si es necesario con la asistencia de un intérprete pagado por el Estado de llegada, al objeto de que pueda, en su caso, formular una solicitud de asilo. Esto supondrá para el retenido el derecho de llenar un formulario tras haber recibido informaciones oportunas sobre el procedimiento que debe seguirse en un idioma de su comprensión. A partir de entonces, toda devolución «en la puerta del avión» se considerará inadmisible; c) Toda restricción a la libertad de movimiento deberá seguir constituyendo una excepción. Donde sea posible, la privación de libertad deberá sustituirse por otras medidas de vigilancia, como la provisión de garantías o de fianza, o medidas similares. En los casos en que la retención es el único medio de asegurar la presencia física de un extranjero, no deberá efectuarse sistemáticamente en una comisaría de policía o en una prisión, con la salvedad de imposibilidad material. Del mismo modo, la retención no deberá superar la duración estrictamente necesaria para organizar la transferencia del detenido a un centro especializado; d) Deberá concederse a los extranjeros detenidos el derecho de ponerse en contacto con las personas de su elección para informarle de su situación.

Asimismo, la recomendación recoge ciertas directrices respecto de las condiciones de detención, ya que, en la medida de lo posible, a) los Estados miembros deberán armonizar las legislaciones, por una parte, relativas a las garantías de procedimiento concedidas a los extranjeros que sean objeto de una medida de retención y, por otra, a la duración máxima de retención en cada etapa del procedimiento; b) deberían evitar proceder a retenciones en las zonas de espera de menores no acompañados, mujeres embarazadas, madres con niños pequeños, personas de edad avanzada y discapacitados. Un menor no acompañado deberá ser albergado, en su caso, en un centro especia-

${ }^{23} \mathrm{https}$ //wcd.coe.int/ViewDoc.jsp?id=980219\&BackColorInternet=FEC65B\&BackColorIntranet=FEC65B\&BackColorLogged=FFC679. 
lizado, y su situación deberá ser inmediatamente examinada por las autoridades judiciales. No deberá separarse a los miembros de una misma familia; c) Los extranjeros retenidos que estén pendientes de una autorización deberán ser albergados en un centro especializado y, bajo ningún concepto deberá albergarse a los mismos durante su retención junto a prisioneros comunes. Esto es igualmente aplicable a los extranjeros pendientes de la ejecución de una orden de expulsión, con la salvedad, evidentemente, de las personas expulsadas tras haber cumplido su pena y las personas retenidas en la frontera con vistas a su extradición; d) Las personas retenidas, con independencia de la duración de su retención, tendrán derecho a la asistencia médica de urgencia que exija su estado de salud; e) De ninguna manera debe considerarse que los centros de retención son similares a centros penitenciarios; $\mathrm{f}$ ) Las autoridades nacionales deberán garantizar una transparencia máxima del funcionamiento de los centros de retención, reconociendo cuando menos un derecho de acceso a tales centros a las comisiones nacionales independientes, los defensores del pueblo o las ONG, los abogados o los padres de los retenidos. Ante todo deberá asegurarse un control regular, por parte de la autoridad judicial, del funcionamiento de estos centros; g) No solamente es indispensable garantizar, sino también asegurar en la práctica, el derecho de ejercer un recurso judicial, tal como prevé el artículo 13 del $\mathrm{CEDH}$, en los casos en que la persona afectada alegue que las autoridades competentes han violado, o puedan violar, uno de sus derechos garantizados por el CEDH. Este derecho a un recurso efectivo deber garantizarse a todo aquel que desee recurrir una decisión de rechazo o de expulsión del territorio. Este recurso deberá suspender la ejecución de una decisión de expulsión, al menos en los casos en que se alega una posible violación de los artículos 2 y 3 del CEDH.

Por último, la Recomendación del Comisario se refiere a las condiciones mínimas de la ejecución de medidas de expulsión: a) en caso de que deba procederse a la expulsión forzosa, ésta deberá realizarse con arreglo a un proceso absolutamente transparente, que permita asegurar que se han respetado los derechos fundamentales de la persona en todas las etapas; b) El mejor modo de evitar en todos los casos el uso de métodos que podrían traumatizar tanto a las personas expulsadas como a los responsables de ejecutar las decisiones de expulsión consiste en que la persona afectada convenga en regresar voluntariamente; c) Siempre que deba ejecutarse una decisión de expulsión, es crucial en todas las fases del proceso informar a las personas afectadas de lo que les espera, al efecto de que puedan prepararse psicológicamente para la idea del regreso. Las expulsiones colectivas están 
prohibidas, tal como estipula el artículo 4 del Protocolo 4 del CEDH; e) No deberá amenazarse a las personas que sean objeto de una orden de alejamiento para persuadirles a subir a un medio de transporte. Estará absolutamente prohibido llevar máscaras que impidan identificar al personal encargado de la ejecución de una medida de expulsión forzosa; f) Deberá impartirse una formación adecuada al personal de los centros de retención y los funcionarios de los servicios de inmigración o de escolta, a fin de reducir al mínimo el riesgo de malos tratos; g) Deberán prohibirse por completo lo siguiente:

- el uso de todo medio que pueda provocar asfixia o sofocación (por ejemplo cinta adhesiva, mordazas, cascos y cojines) y el uso de gas invalidante o irritante; también debe evitarse el uso de sujeciones que puedan provocar asfixia postural;

- el uso de tranquilizantes o inyecciones sin un reconocimiento médico previo o la receta de un médico;

Por último, en relación con las medidas de expulsión, por motivos de seguridad, debería prohibirse el uso en el avión de esposas o sujeciones en personas que se resistan a la expulsión, al menos durante el despegue y el aterrizaje.

Por otra parte, el 9 de noviembre de 2005, el Comisario presentó Su INFORME SOBRE SU VISITA A ESPAÑA. En el mismo dedica una parte, la $\mathrm{V}$, a la inmigración y al asilo. Merecen ser destacados los siguientes aspectos de este informe:

Por lo que se refiere a los Centros de Retención de extranjeros (CRE), en relación con algunos ellos, concretamente el de Moratalaz (Madrid) y el de la Verneda (Barcelona), el Comisario denuncia que las condiciones materiales de los mismos dejan mucho que desear y exigen mejoras importantes y urgentes; asimismo se dan condiciones graves de superpoblación, las habitaciones son oscuras, poco aireadas y no disponen ni de lavabos, ni de water ni de duchas. Los espacios comunes son muy reducidos y hay poca posibilidad de hacer ejercicio. En cualquier caso, el Comisario constata la previsión de cambiar estos centros por otros que reúnen las condiciones mínimas exigibles.

Constata la existencia de una cierta concepción penitenciaria de su organización y que los elementos de seguridad priman sobre otras consideraciones. En este sentido, recuerda que no debe perderse de vista que la retención es una medida de precaución, preventiva y excepcional. Que no puede, en ningún caso, ser entendida como modo de limitar los derechos fundamentales de los extranjeros, aparte, evidentemente, del derecho a la libertad de movimientos. 
Uno de los principales problemas que se ponen de evidencia es la suerte de los extranjeros que, tras un período máximo de retención de 40 días sin haber sido expulsados (por no tener papeles y por la falta de cooperación por parte de los consulados para identificar a las personas y de tratados bilaterales de readmisión con España), deben ser puestos en libertad sin que sea posible adoptar una nueva medida de retención por los mismos motivos. Esto provoca que importantes grupos de inmigrantes se encuentren en territorio español de forma irregular. Esta situación tiene graves consecuencias en el plano humanitario y social ${ }^{24}$ y representa un problema importante para el Estado Español que no puede mantenerse impasible ante la existencia sobre el territorio de un colectivo de extranjeros en situación irregular ${ }^{25}$.

Otro aspecto sorprendente es la falta de información a los extranjeros sobre su situación y la dificultad de acceso a un abogado.

Por lo que se refiere al proceso de reenvío y expulsión, el Comisario critica que no siempre se cumplan la previsiones legales; asimismo critica que no se contemple en el reglamento de aplicación la norma internacional según la cual una persona no puede ser expulsada o reenviada a un país en el que su vida o su libertad corre peligro por razones de raza, religión, nacionalidad, pertenencia a un grupo social determinado o por sus opiniones políticas ${ }^{26}$.

Por lo que se refiere al proceso de regularización y normalización realizado por el Gobierno español, el Comisario felicita a la administración por considerar que se trata de un importante esfuerzo por parte de ésta para controlar y regularizar la inmigración ilegal y, sobre todo, para poner fin al trabajo ilegal y a las inaceptables situación de explotación que se producen ${ }^{27}$.

${ }^{24}$ Algunas ONGs y los Servicios Sociales de las Comunidades Autónomas afectadas les prestan habitualmente cierta forma de asistencia, como una ayuda de primera necesidad y acogida en los lugares de acogida temporal - donde se les ofrece alojamiento, la posibilidad de asearse, ropa, asistencia sanitaria y consejos - se trata de medidas paliativas que no solucionan la cuestión de fondo; vid. RAPPORT DE M. ALVARO GIL-ROBLES, COMMISSAIRE AUX DROITS DE L'HOMME SUR SA VISITE EN ESPAGNE (10-19 MARS 2005) [Doc. CommDH(2005)8], par. 82.

https://wcd.coe.int/ViewDoc.jsp?id=927685\&BackColorInternet=FEC65B\&BackColorIntranet $=$ FEC65B \&BackColorLogged $=$ FFC679

258.716 personas fueron liberadas en 2004 y alrededor de 3.000 en la primera parte del año 2005; vid. RAPPORT DE M. ALVARO GIL-ROBLES, COMMISSAIRE AUX DROITS DE L'HOMME SUR SA VISITE EN ESPAGNE (10-19 MARS 2005) [Doc. CommDH(2005)8], par. 83.

${ }^{26}$ Ibid., par. 86.

27 Ibid., par. 89 . 
En relación con los menores extranjeros no acompañados, éstos están sometidos a riegos y problemas especiales, muchos de los cuales derivan de la falta de coordinación de las diferentes administraciones implicadas.

En materia de asilo y refugio, el comisario compele al Gobierno para que se adapte la normativa española, que data de 1984, a la directiva comunitaria de 29 de abril de 2004 .

Dedica el informe mayor atención a Canarias, Ceuta y Melilla debido a que, junto a Andalucía, constituyen los puertos principales de entrada de inmigrantes irregulares ${ }^{28}$.

\section{LA COMISIÓN EUROPEA PARA EL RACISMO Y LA INTOLERANCIA (ECRI)}

Fue creada por una decisión de la Primera Cumbre de Jefes de Estado y de Gobierno del Consejo de Europa celebrada en Viena en 1993. Desde 1994 está funcionado, con sede en Estrasburgo, está compuesta por expertos independientes e imparciales. Una de las labores de la comisión es la realización de informes por países. Así el 21 de febrero de 2006 se presentó el Tercer informe de la ECRI sobre España, en el que son interesantes algunas de las referencias realizadas en relación con el racismo y la discriminación contra los inmigrantes que se encuentran en territorio español, esencialmente respecto de las «personas procedentes del Âfrica Subsahariana que tratan de llegar a territorio español a través de Ceuta y Melilla» ${ }^{29}$.

Así la ECRI afirma que ha recibido informes coherentes sobre posibles patrones de discriminación en el sistema de justicia penal. Según éstos, los no ciudadanos (en particular, marroquíes, sudamericanos e inmigrantes del África Subsahariana), los romaníes y los ciudadanos españoles de origen inmigrante son desproporcionadamente objeto de detenciones, de controles de documentación de identidad y de registros por parte de los representantes de las fuerzas del orden. También son más susceptibles de ser víctimas de malos tratos por parte de dichas fuerzas, especialmente debido a que la práctica de establecer perfiles étnicos está bastante extendida entre las fuerzas

\footnotetext{
${ }^{28}$ Ibid., par. 102-136.

29 Vid. CACHo SÁncheZ, Y.: «La práctica reciente del Consejo de Europa en la lucha contra la discriminación racial: el nuevo informe de la ECRI sobre el racismo en España y las últimas sentencias del TEDH en el marco del artículo 14 del CEDH», en $R G D E$, n. $^{\circ} 10$, mayo 2006, (www.iustel.com).
} 
policiales españolas, sobre todo entre las que actúan en el ámbito municipal ${ }^{30}$.

Por otra parte, aborda la problemática relativa a la acogida y condición jurídica de los no nacionales, la relacionada con los centros de internamiento, con los menores no acompañados y con las mujeres víctimas de trata de seres humanos, al igual que se ocupa de la violencia racial y de otros actos discriminatorios que afectan a diferentes aspectos de la vida cotidiana de los miembros de los grupos minoritarios en España, a saber, vivienda, empleo, educación, etc.

En otro orden de cosas, señala su preocupación respecto de algunos aspectos de la Ley Orgánica 4/2000 sobre derechos y libertades de los extranjeros. Así, muestra el informe sus reservas respecto de la no concesión a los trabajadores ilegales del derecho de sindicación y de huelga (aunque comprende que el Tribunal Constitucional no se haya todavía podido pronunciar al respecto), la atribución de poderes a la policía para que acceda a los registros municipales en los que los inmigrantes deben estar registrados para poder acceder a los servicios sociales (pues podría limitar su acceso a estos servicios), o la atribución de responsabilidades de control fronterizo a empresas transportistas.

Asimismo, le preocupa la disposición del Código Penal introducida por la Ley Orgánica 11/2003 (de medidas concretas en materia de seguridad ciudadana, violencia doméstica e integración social de los extranjeros) que prevé la expulsión inmediata de un no ciudadano acusado, pero no declarado culpable, de cometer un delito penado con un máximo de seis años de prisión, sin tener en cuenta los vínculos de esa persona con la sociedad española (aunque entiende que se ha derogado tras una sentencia del Tribunal Supremo).

Por otra parte, expresa su inquietud ante informes recibidos según los cuales las personas procedentes del África Subsahariana que tratan de llegar a Ceuta y Melilla son con frecuencia víctimas de malos tratos y abuso verbal por parte de las autoridades fronterizas y los funcionarios de los servicios policiales y que incluso se les expulsa sin respetar el procedimiento establecido por la ley de deportaciones y sin tener en cuenta que son solicitantes potenciales de asilo.

Igualmente, muestra su preocupación porque, a pesar de que, desde su segundo informe, las condiciones de vida en los centros de internamiento de las islas Canarias han mejorado, se le ha notificado

${ }^{30}$ Ibid. 
que las personas retenidas en los centros de internamiento españoles siguen sin tener acceso adecuado a información y asistencia jurídica, situación que afecta negativamente a los solicitantes potenciales de asilo, a lo que se añade la conducta de las autoridades policiales y fronterizas, que algunas veces parecen ignorar las solicitudes de asilo.

La inquietud de la ECRI también se debe a que, según los informes recibidos, los menores no acompañados han sido repatriados en algunos casos sin verificar previamente que regresarían a su familia o a las instituciones apropiadas en su país de origen, e incluso han sido víctimas de malos tratos por parte del personal o de otros niños durante su estancia en centros de acogida o por parte de las fuerzas policiales durante su traslado, especialmente en Ceuta y Melilla.

La problemática relativa a las mujeres que han sido víctimas de trata en España al objeto de su explotación sexual ha merecido un tratamiento específico por parte de la ECRI. En particular, ha recomendado a las autoridades españolas que garanticen su protección y acceso, cuando sea necesario, a permisos de residencia, con independencia de su voluntad de denunciar a los traficantes, de testificar contra ellos o de proporcionar información esencial para enjuiciarles, a diferencia de lo que ocurre en la actualidad.

\section{EL COMITÉ EUROPEO PARA LA PREVENCIÓN DE LA TORTURA Y DE LAS PENAS Y TRATOS INHUMANOS O DEGRADANTES (CPT)}

El mecanismo utilizado por el CPT es de carácter preventivo y no judicial por lo que puede considerarse que aporta un complemento importante al sistema de protección existente en el marco del CEDH que en su artículo 3 prohíbe la tortura y las penas o tratos inhumanos y degradantes.

Como hemos afirmado anteriormente, el Comité tiene competencia para visitar cualquier lugar donde se encuentren personas detenidas; por ello en sus visitas a los Estados, normalmente realiza investigaciones en centros de retención de extranjeros, entre otros.

A fin de ver cuales son las opiniones del CPT nos remitimos al documento Normas del CPT. Secciones de los Informes Generales del CPT dedicadas a cuestiones de fondo (Doc. CPT/Inf/E (2002) 1Rev. 2004) $)^{31}$, en el que recoge una referencia concreta a los ex-

31 http://www.cpt.coe.int/lang/esp/esp-standards.doc. 
tranjeros. Una de las críticas del CPT se refiere a los zonas de tránsito o "zonas internacionales» de los aeropuertos dado que, a pesar de que los Estados afirman que las personas que se encuentran en dichas zonas son libres de abandonarlas en cualquier momento para embarcar en cualquier vuelo internacional, el Comité considera que la permanencia en estas zonas supone una violación del artículo 5.1.f del $\mathrm{CEDH}^{32}$. Asimismo, el Comité vierte sus críticas sobre los puntos de detención en los puntos de entrada de inmigrantes, respecto de las comisarías de policía, de los establecimientos específicos de retención, así como respecto de las prisiones, ya que en ocasiones estos inmigrantes son recluidos en prisiones. Por último, el comité hace referencia a la deportación de extranjeros por vía aérea.

\section{EL TRIBUNAL EUROPEO DE DERECHOS HUMANOS}

No parece que sea necesario profundizar en la importancia que la jurisprudencia del Tribunal Europeo de Derechos Humanos reviste en el momento actual. Y es que, por una parte, supone el parámetro interpretativo de los derechos humanos tanto para los tribunales nacionales $^{33}$, como para la propia UE, y por otra, representa la última garantía del disfrute de los derechos fundamentales por parte de aquellos individuos, nacionales o extranjeros, que se encuentran en el territorio de un Estado miembro del Consejo de Europa. De esta afirmación general se deduce que los migrantes pueden encontrar en el Tribunal la posibilidad de ver respetados sus derechos y de que la violación de éstos sea condenada.

A pesar de que, como ya hemos afirmado, el CEDH no hace referencia expresa a los derechos de los migrantes, lo cierto es que partiendo de una interpretación extensiva de los derechos recogidos en el

32 El CPT se basa en la sentencia del TEDH en el asunto Amuur c. Francia, de 25 de junio de 1996, en la que el Alto Tribunal estableció que «el mero hecho de que sea posible para los solicitantes de asilo abandonar voluntariamente el país en el que deseaban refugiarse no puede excluir una restricción de su libertad..." y mantuvo que "la detención de los solicitantes en la zona de tránsito... era equivalente en la práctica, desde el punto de vista de las restricciones sufridas, a una privación de libertad»; vid. Normas del CPT. Secciones de los Informes Generales del CPT dedicadas a cuestiones de fondo (Doc. CPT/Inf/E (2002) 1- Rev. 2004), p. 41.

33 Sirva como ejemplo nuestra Constitución que, de forma indirecta, en su artículo 10.2 se refiere al CEDH como base interpretativa de los derechos recogidos en nuestra Carta Magna. Prueba de ello es la continua referencia de los Tribunales españoles a la jurisprudencia del TEDH como argumentación de sus decisiones. 
mismo y de una consideración restrictiva de las limitaciones de estos derechos ${ }^{34}$, el TEDH se ha pronunciado en muchas ocasiones en relación con derechos de los que eran titulares inmigrantes, bien regulares, bien irregulares ${ }^{35}$.

Algún autor habla de la técnica de la "protección de rebote», a partir de la cual se permite a la jurisdicción de Estrasburgo ampliar la aplicabilidad de determinados derechos ${ }^{36}$. Y es que a partir de los asuntos Abdulaziz, Cabales y Balkandali c. Reino Unido (1985) y Soering c. Reino Unido (1989), la Corte se ha lanzado a la protección de determinadas categorías de víctimas que en principio parecería no poder invocar la violación de un derechos convencionalmente garantizado. Así, con base en esta teoría, dado que la CEDH no garantiza de forma directa a los extranjeros el derecho de entrar y permanecer en el territorio de un Estado Parte, los artículos 3 y 8 de este texto - que prohíben los malos tratos y garantizan la vida familiar, deben ser tomados en consideración para apreciar la legitimidad de las medidas de denegación de entrada o residencia en el territorio de un Estado ${ }^{37}$.

Los pronunciamientos del Tribunal se han centrado en determinados derechos concretos que pasamos a analizar brevemente a continuación.

A. Derecho a no sufrir tratos o penas inhumanos y degradantes (art. 3 CEDH). El Tribunal ha considerado que este artículo consagra uno de los valores fundamentales de las sociedades democráticas y, por tanto, prohíbe tales prácticas en cualquier circunstancia y contra cualquier persona ${ }^{38}$.

Quizá uno de los pronunciamientos más importantes en esta línea sea el vertido en el Asunto Soering c. Reino Unido. En el mismo, el TEDH subrayó que el art. 3 representa «uno de los valores fundamentales de las sociedades democráticas que forman el Consejo de

${ }^{34}$ Vid. Eudes, M.: La pratique judiciare interne de la Cour Europeenne des Droits de l'Homme, Paris, Pedone, 2005, p. 414.

35 Guiraudon, V.: «European Courts and Foreigners' Rights: A Comparative Study of Norms Diffusion", en IMR, Vol. 34, N. 4, Winter 2000, p. 1096.

${ }_{36}$ Vid. Eudes, M.: La pratique judiciare interne de la Cour Europeenne des Droits de l'Homme, op. cit., 416.

37 Ibid.

38 Vid. Castillo Daudí, M.: Derecho Internacional de los Derechos Humanos, op. cit., pp. 123-124; LEACH, P.: Taking a Case to the European Court of Human Rights, $2^{\text {nd }}$ Edition, Oxford University Press, 2005, pag. 201. 
Europa $»^{39}$. Y es que este artículo ha sido definido como un derecho intangible, absoluto, perteneciente al núcleo duro de la Convención, por lo que no puede sufrir ninguna excepción. Por ello, en el caso de los extranjeros, el comportamiento de los mismos no tiene ninguna importancia ya que «la Convención prohíbe en términos absolutos la tortura o las penas o tratos inhumanos o degradantes, independientemente de quien sea la víctima ${ }^{40}$.

Este artículo ha sido interpretado por el Alto Tribunal en el sentido de prohibir a los Estados parte de la CEDH el «alejamiento» (ya sea por expulsión, extradición o repatriación) de su territorio en aquellos casos en que la medida tenga por efecto someter al extranjero a un riesgo serio de sufrir un trato contrario a este precepto en el país de destino ${ }^{41}$. Así en el Asunto Vilvarajah y otros c. Reino Unido (30 de octubre de 1991), la Corte afirmó que «la expulsión de un demandante de asilo por un Estado contratante puede suponer un problema a la vista del art. 3 en el sentido de comprometer la responsabilidad del Estado en cuestión [...] si hay motivos serios y suficientes para creer que el interesado correrá, en el país de destino, un riesgo real de ser sometido a tortura o a penas y tratos inhumanos y degradantes $»^{42}$. Esta opinión es mantenida por el Tribunal incluso en aquellos casos en que el extranjero sea culpable de importantes delitos ${ }^{43}$.

Además, si combinamos el artículo 3 con el artículo 1 de la CEDH debemos afirmar que la obligación que se contiene es doble: por un

39 Vid. Asunto Soering c. Reino Unido (7 de julio de 1989), par. 88. (http://www.echr.coe.int/ECHR/).

${ }_{40}$ Vid. Asunto Soering c. Reino Unido (7 de julio de 1989), par. 79-81, Asunto Vilvarajah $y$ otros $c$. Reino Unido (30 de octubre de 1991), par. 108. (http://www.echr.coe.int/ECHR/)

${ }^{41}$ Vid. CARLIER, J-Y. ET SAROLÉA, S.: "Évolutions Jurisprudentielles», en Inmigration and Asylum Law of the EU: current debates , op. cit., p. 13; GUIRAUDON, V.: "European Courts and Foreigners' Rights: A Comparative Study of Norms Diffusion", op. cit., p. 1097; LEACH, P.: Taking a Case to the European Court of Human Rights, $2^{\text {nd }}$ Edition, op. cit., p. 212; Renucci, J.-F.: Droit Européen des droits de l'homme, Cedex, Paris, 1999, pp. 213-214. entre otros, así lo ha afirmado el tribunal en el Asunto Ahmed c. Austria, 17 de diciembre de 1996, Asunto Hilal c. Reino Unido, 6 de marzo de 2001, Asunto Thampibillai c. Países Bajos, 17 de febrero de 2004 y Asunto Venkadajalasarma c. Países Bajos, 17 de febrero de 2004.

42 Asunto Vilvarajah y otros c. Reino Unido (30 de octubre de 1991), par. 108. (http://www.echr.coe.int/ECHR/)

${ }_{43}$ GuIRAudoN, V.: «European Courts and Foreigners' Rights: A Comparative Study of Norms Diffusion", op. cit., p. 1097. Al respecto, Asunto Moustaquim c. Bélgica (18 de febrero de 1991); Asunto Beldjoudi c. Francia (26 de marzo de 1992); Asunto Nasri c. Francia (13 de julio de 1995) y Asunto Berrehab c. Países Bajos (21 de junio de 1988). 
lado, se prohíbe a los Estados imponer tratos inhumanos y degradantes (obligación negativa), por otro, se impone a los Estados proteger a los individuos que se encuentren bajo su jurisdicción contra los tratos inhumanos y degradantes ${ }^{44}$. Por otra parte, por lo que se refiere al autor de los malos tratos, el Tribunal ha tomado en consideración cualquier maltrato, independientemente del origen de la amenaza (autoridades locales, poderes de facto e incluso agentes no estatales) $)^{45}$. Incluso, el TEDH ha tomado en consideración en estos supuestos los maltratos resultantes de factores materiales independientes de la responsabilidad de las autoridades del país de origen en el caso de entrega de un extranjero a un país en el que no puede ser atendido correctamente, siempre que se demuestre que el tratamiento no existe en el país de origen del extranjero y que se encuentre muy grave o en el final de su vida ${ }^{46}$.

Por otra parte, combinando el artículo 3 con el artículo 4 de la $\mathrm{CEDH}$, el TEDH ha afirmado que la expulsión de una persona a un país en que existe un régimen de esclavitud puede suponer violación del artículo $3^{47}$.

Por último, debe ser resaltado que en todos estos supuestos se trata de una violación virtual del artículo 3, ya que ésta sólo se producirá en caso de que efectivamente se realice la expulsión o extradición ${ }^{48}$.

\section{B. Derecho a no ser sometido a esclavitud y trabajos forzados} (art. 4 CEDH). Este artículo prohíbe la esclavitud y los trabajos forzados salvo en los casos previstos en el propio artículo. La esclavitud y la trata de seres humanos es un gran problema de la sociedad actual que afecta, en mayor medida, a las poblaciones migrantes, funda-

44 Al respecto de la doble naturaleza de las obligaciones de la CEDH nos remitimos a CASTRO SÁNCHEZ, C. DE: "Nuevas formas de esclavitud: mujeres inmigrantes y trabajo doméstico. Comentario de la Sentencia del TEDH, Siliadin c. Francia, de 26 de julio de 2005, en $R G D E$, vol. 8, octubre 2005, (http://www.iustel.com).

45 Asunto Chahal c. Reino Unido, 15 de noviembre de 1997, y Asunto Ammari c. Suecia, 22 octubre 2002, (http://www.echr.coe.int/ECHR/); vid. LEACH, P.: Taking a Case to the European Court of Human Rights, $2^{\text {nd }}$ Edition, Oxford University Press, 2005, p. 213.

46 Vid. Asuntos Yildiz c. Alemania (12 diciembre de 2002; Karagoz c. Francia (15 noviembre 2001), Javanmardi c. Suecia (19 marzo 2002). (http://www.echr.coe.int/ECHR/)

47 Asunto Ould Barar c. Suecia, 16 de enero de 1999, (http://www.echr.coe.int/ECHR/).

48 Vid. Puente Egido, J.: Casos Prácticos de Derecho Internacional Público, Madrid, 1997, pp. 254-264; RENUCCI, J.-F.: Droit Européen des droits de l'homme, Cedex, Paris, 1999, p. 213. 
mentalmente a un grupo vulnerable dentro de esta categoría que son las mujeres menores de edad migrantes.

Esta problemática se puso de evidencia en el Asunto Siliadin c. Francia (26 de julio 2005) ${ }^{49}$. Siwa-Akofa Siliadin, natural de Togo, llegó a Francia el 26 de enero de 1994, contando quince años de edad y desde ese momento, hasta que la policía intervino el 28 de julio de 1998 fue víctima de esclavitud moderna. Son varias las cuestiones de interés que se desprenden de esta sentencia.

Por una parte, afirmó la sentencia que respecto de algunos artículos de la Convención, el hecho de que el Estado se abstenga de atentar contra los derechos garantizados no es suficiente para concluir que se cumple con las obligaciones impuestas por el artículo 1 de la Convención. Afirma el TEDH que en el caso de los artículos 2, 3 y 4 del Convenio Europeo, dado que se trata de valores fundamentales de las sociedades democráticas que forman el Consejo de Europa, la obligación positiva que concierne a los Estados comprende, además de la adopción de las medidas legislativas internas necesarias para la protección y garantía de los derechos recogidos en estos artículos, la adopción de medidas dirigidas a impedir la comisión de los actos prohibidos, tanto por las autoridades como por personas privadas. Tales imperativos adquieren una mayor relevancia en el caso de que la víctima de los actos prohibidos sea un menor de edad.

Por otra parte, por lo que se refiere al contenido material del propio artículo 4, debemos partir de la afirmación de que la prohibición de la esclavitud, de la servidumbre y de los trabajos forzados es un derecho absoluto que no puede ser derogado en ninguna circunstancia ( $\$ \S 70,90$ y 112). Además, en torno al propio contenido del artículo 4 , dos son los aspectos que deben tenerse en cuenta, el propio concepto de esclavitud o servidumbre y, el nivel de protección debido atendiendo a elementos tales como la edad o la vulnerabilidad de la posible víctima. En este sentido, del fallo del Tribunal en el Asunto Siliadin c. Francia puede concluirse que entre los elementos valorativos a tener más en cuenta para determinar la ilicitud de las conductas se encuentran la minoría de edad y la vulnerabilidad del sujeto. Esta última vendrá dada esencialmente por la condición de mujer y la condición de inmigrante.

49 Para un comentario en detalle de esta sentencia nos remitimos a CASTRO SANCHEZ, C. DE: «Nuevas formas de esclavitud: mujeres inmigrantes y trabajo doméstico. Comentario de la Sentencia del TEDH, Siliadin c. Francia, de 26 de julio de 2005", op. cit. 
C. Derecho a la libertad (art. 5 CEDH)). La Corte ha aplicado a las retenciones de inmigrantes su jurisprudencia según la cual no todo atentado a la libertad implica privación de libertad. Así, en la materia que nos ocupa es interesente el pronunciamiento de la Corte respecto de las «zonas internacionales» de los aeropuertos en el caso Amuur, en el sentido de entender que si bien no hay detención de inmigrantes, lo cierto es que supone una restricción a su libertad ${ }^{50}$.

Asimismo, el tribunal ha hecho referencia en sus pronunciamientos a la dificultad para el planteamiento de recursos por parte de los inmigrantes (art. 5.4).

D. Derecho al respeto de la vida privada y familiar (art. 8 CEDH). El artículo implica tanto una obligación negativa para el Estado, no atentar contra la vida privada y familiar, como una obligación positiva, velar por el respeto efectivo de la vida privada. Una de las cuestiones más importantes puestas de manifiesto por el propio tribunal es la noción de vida familiar y privada. Así, la jurisprudencia en materia de inmigración subraya que un vínculo familiar existe siempre entre una persona y sus hijos menores, independientemente de que vivan juntos o no (por encarcelamiento, separación de los padres o circunstancias excepcionales) ${ }^{51}$ y ha utilizado generalmente un concepto de familia amplia (inclusiva de la familia legítima, familia natural y aceptando situaciones de hecho) ${ }^{52}$. Por tanto, en caso de expulsión (por el motivo que sea) son varias las circunstancias que deben tenerse en cuenta para no incurrir en violación del artículo 8, así, "la naturaleza y la gravedad de la infracción cometida por el recurrente, la duración de su estancia en el país de cuyo territorio va a ser expulsado, el período que ha transcurrido desde la per-

50 En el Asunto Amuur c. Francia, sentencia de 20 de mayo de 1996, el Tribunal afirmó que la retención de extranjeros en las zonas internacionales de los aeropuertos implicaba una restricción a su libertad. Sólo puede considerarse aceptable esta restricción cuando reúna las garantías necesarias y tenga como objetivo la lucha contra la inmigración ilegal. En cualquier caso, debe respetar las normas internacionales que vinculen al Estado en la materia. Por otra parte, si la decisión de retención, adoptada por la autoridad administrativa o policial competente, debe ser prolongada, será necesaria la intervención judicial a fin de que se garanticen los derechos de la persona retenida. Vid. CASTILlo Daudí, M.: Derecho Internacional de los Derechos Humanos, op. cit., pp. 129 y 130.

${ }^{51}$ Asunto Ahmut c. Países Bajos, 28 de noviembre de 1996, Asunto Al-Nasif c. Bulgaria, 20 de junio de 2002, Asunto C c. Bélgica, 7 de agosto de 1996, Asunto Berrehab c. Países Bajos, 21 de junio de 1988, Asunto Sen c. Países Bajos, 21 de diciembre de 2001.

${ }^{52}$ Asunto Marcks c. Bélgica, Vid. Renucci, J.-F.: Droit Européen des droits de l'homme, Cedex, Paris, 1999, p. 215. 
petración de la infracción así como la conducta del interesado durante ese período, la situación familiar [duración de su matrimonio, otros elementos determinantes de la vida en común de una pareja, el nacimiento de hijos, la edad de los hijos, la gravedad de las dificultades con las que el cónyuge podría encontrarse en el país de destino en caso de expulsión, etc...]. En cualquier caso, el vínculo familiar ha de ser real y efectivo ${ }^{53}$.

En cualquier caso, el fin del artículo 8 es la protección de la vida familiar ya existente, por lo que no supone violación de este artículo el hecho de impedir la entrada de un extranjero en un Estado para que cree su vida familiar o expulsarlo teniendo en cuenta que puede reconstruir su familia en otro lugar ${ }^{54}$.

E. Prohibición de expulsiones colectivas (art. 4 del Protocolo 4 al CEDH). Este artículo prohíbe «toda medida que obligue a los extranjeros, en tanto que grupo, a abandonar un país, salvo en los casos en que tal medida se adopte en el marco y sobre la base de un examen razonable y objetivo de la situación particular de cada extranjero que forma el grupo». En sus pronunciamientos la Corte debe tener en consideración las circunstancias que rodean la adopción de la decisión de expulsión.

Así, en el Asunto Conka c. Bélgica (5/02/2002), la Corte afirma que a pesar de que las decisiones habían sido adoptadas tras un examen de la situación personal de cada uno de los interesados, la decisión de abandono del territorio estaba motivada de manera estereotipada, sin referencia a la situación personal de los extranjeros concernidos. Asimismo, la Corte pone de relieve que un gran número de personas del mismo origen habían corrido la misma suerte, lo que indica que no puede excluirse de la naturaleza del proceso seguido toda duda sobre el carácter colectivo de la medida. Las dudas además se acrecientan al comprobar la existencia de un anuncio político previo sobre operaciones de este tipo, anuncio acompañado de instrucciones a las administraciones en este sentido, por la simultaneidad de las convocatorias, por la dificultad de los inmigrantes de acudir a un abogado y por que sus procedimientos de asilo no ha-

53 Asunto Barrehab c. Países Bajos, 26 de septiembre de 1997, Asunto Mehemi c. Francia, 26 de septiembre de 1997; Vid. LEACH, P.: Taking a Case to the European Court of Human Rights, $2^{\text {nd }}$ Edition, op. cit., pags. 303-306; RENUCCI, J.-F.: Droit Européen des droits de l'homme, op. cit., p. 215.

${ }^{54}$ Vid. LEACH, P.: Taking a Case to the European Court of Human Rights, $2^{\text {nd }}$ Edition, op. cit., pag. 303; RENUCCI, J.-F.: Droit Européen des droits de l'homme, op.cit., p. 215. 
bían finalizado. En definitiva, la Corte considera que en ningún momento el procedimiento seguido ofrece las garantías suficientes de que se hayan tenido en cuenta realmente de forma diferenciada la situación individual de cada una de las personas concernidas.

\section{F. Los principios de igualdad y no discriminación (art. 14} CEDH). En los asuntos relativos a inmigración hay una cuestión que ha sido muy discutida, cual es la diferencia de trato basado en la diversa nacionalidad de los inmigrantes. Así, a partir del Asunto Gaygusuz c. Austria (1996), la Corte profundizó en la aplicación de este principio a los extranjeros, esencialmente, a los trabajadores migrantes, al entender que la discriminación respeto de un derecho de seguridad social fundada en la nacionalidad, supone una violación de la Convención ${ }^{55}$.

Para finalizar con este análisis, simplemente queremos apuntar algunas cuestiones en relación con los derechos procesales recogidos en el CEDH. Así, en los procesos en que se han visto involucrados migrantes, se ha alegado el derecho a beneficiarse de un proceso equitativo (artículo $6 \mathrm{CEDH}$ ). Lo cierto es que la aplicabilidad de este artículo a los procedimientos migratorios siempre ha sido contestada por el TEDH entendiendo que, si hacemos una interpretación global, que incluye el artículo 7 del Protocolo $1 .^{\circ}$ a la $\mathrm{CEDH}^{56}$, debemos afirmar la inaplicación del artículo 6 a este tipo de procedimientos, ya que ha sido necesario adoptar un protocolo específico para tales casos. Otro de los derechos alegados por los migrantes ante el Tribunal ha sido el derecho a disponer de un recurso efectivo (artículo $13 \mathrm{CEDH}$ ). Dado que este artículo garantiza el derecho de toda persona a un recurso efectivo en caso de violación de un derecho garantizado por la CEDH, siempre se alega junto a la violación de otro derechos, es decir, no tiene una existencia autónoma. En el caso de los contenciosos de extranjería normalmente se alega junto al artículo 3 y $8 \mathrm{CEDH}$.

\section{A MODO DE RECAPITULACIÓN}

Como queda claro a la luz de las páginas anteriores, la labor del Consejo de Europa en materia de derechos de los inmigrantes reviste

${ }^{55}$ GuILD, E.: La Convention Européenne relative au statut juridique du travailleur migrant (1977). Une analyse de son champ d'application et de sa portée actuelle, mars 1999, (www.coe.int/t/migration/Documentation), p. 5; GuIRAudoN, V.: «European Courts and Foreigners' Rights: A Comparative Study of Norms Difusión», op. cit., p.

${ }^{56}$ Este artículo prevé garantías procesales en materia de expulsión de extranjeros. 
un gran interés. Cierto es que, frente a la proliferación de tratados sobre otras materias en el marco de esta organización, no hay un número elevado de tratados cuyo objetivo sea la protección específica de los derechos de los migrantes. A pesar de que este dato podría suponer una cierta alarma ante la realidad social de la inmigración que vive Europa en estos tiempo, ya ha quedado evidenciado que son varios los órganos del Consejo de Europa que tienen, entre sus objetivos, la promoción de los derechos de ese grupo vulnerable, así como la vigilancia del grado de cumplimiento por parte de los Estados miembros de las obligaciones que les son atribuibles. En especial, en estas últimas palabras, nos gustaría subrayar la labor realizada por el Comité para la prevención de la tortura, en el marco de la Convención Europea para la prevención de la tortura y las penas y tratos inhumanos y degradantes, la Comisión Europea contra el racismo y la intolerancia y el Tribunal Europeo de Derechos Humanos. En relación con este último, no debe pasarse por alto que los pronunciamientos del TEDH han contribuido enormemente a la clarificación de las obligaciones que los Estados tienen respecto de los extranjeros, fundamentalmente en lo que se refiere al respeto de la vida privada y familiar (art. 8 del CEDH) y la prohibición de extraditar a un extranjero a un país en el que corre peligro de ser sometido a tortura o tratos o penas inhumanos y degradantes (art. 3 del CEDH) ${ }^{57}$. La acción del Tribunal tiene incidencia en dos niveles esenciales de actuación frente al problema. Por una parte, a la luz del Tratado de la Unión Europea (art. 6.2), la interpretación de los derechos humanos se hará de conformidad con la jurisprudencia del Tribunal de Estrasburgo. Por otra parte, los Estados europeos, en tanto que Estados parte en el Convenio Europeo de Derechos Humanos, deben cumplir con las sentencias del TEDH que, entre otras cosas, implica la asunción de la interpretación que de los derechos humanos hace este órgano. En algunos casos, esta obligación viene también impuesta por el propio Derecho interno - como ocurre en España-.

Para concluir, querríamos retomar la idea de la que partíamos en este estudio: cualquier solución que se cree para enfrentar el problema de la migración -irregular- en Europa, debe ser necesariamente global e integral, lo que incluye, necesariamente, el respeto de los derechos humanos de los que estos individuos son titulares.

57 GuILD, E.: La Convention Européenne relative au statut juridique du travailleur migrant (1977). Une analyse de son champ d'application et de sa portée actuelle, op. cit., p. 3 . 